\title{
Rate and duration of hospitalisation for acute pulmonary embolism in the real-world clinical practice of different countries: analysis from the RIETE registry
}

\author{
To the Editor:
}

The latest guidelines suggest considering home treatment or early hospital discharge in low-risk mortality pulmonary embolism (PE) patients, identified through widely validated clinical prediction rules $[1,2]$. Nevertheless, it is still not clear if these patients are really treated on an outpatient basis in clinical practice.

Thus, we used the RIETE registry (ClinicalTrials.gov identifier: NCT02832245) to assess the proportion of outpatients with acute PE initially treated in-hospital, the mean duration of hospitalisation and to identify predictors for home treatment or for early discharge. We included data from 11473 patients registered in 25 countries participating in the RIETE study from January 2010 to December 2016. Both local and academic hospitals were involved. Rate and duration of hospitalisation for acute PE in the four countries with highest enrolment and in other participating countries, grouped together as a unique group, were compared. Namely, patients enrolled in Spain $(n=8270)$ were compared with those included in France $(\mathrm{n}=964)$, Italy $(\mathrm{n}=593)$, Israel $(\mathrm{n}=429)$ and in "other countries" $(\mathrm{n}=1217)$.

All the variables potentially associated with outpatient treatment and with early discharge (length of in-hospital stay (LOS) $\leqslant 5$ days) were evaluated at the univariate analysis using the Mann-Whitney test (for continuous variables) and the Chi-squared or Fisher's exact tests (for dichotomous variables). Statistically or marginally significant variables $(\mathrm{p}<0.10)$ were introduced in a multivariate model (backward binary logistic regression model). The role of different scores, such as the Pulmonary Embolism Severity Index (PESI) [3], the RIETE score [4] and the scheme suggested by the American College of Chest Physicians guidelines (ACCP scheme) for the bleeding risk [2], was assessed performing three different sensitivity analyses, excluding all the variables already included in each score. SPSS software (version 15; SPSS Inc., Chicago, IL, USA) was used for statistical analysis. A two-sided p-value of 0.01 was considered to be statistically significant.

A significantly lower proportion of complete outpatient treatment was found among PE subjects treated in Spain $(2.5 \%)$, France $(1.2 \%)$ and Israel $(0.99 \%)$ than among those treated in Italy and the other countries ( $16 \%$ and $21 \%$, respectively, $\mathrm{p}<0.001$ for both). By contrast, the number of patients discharged within 5 days was significantly lower in Italy (23\%), Spain (26\%) and France (28\%) than in Israel and the other countries examined ( $48 \%$ and $32 \%$, respectively, $\mathrm{p}<0.001$ for both). The mean LOS was substantially shorter in Israel (median (interquartile range) $6(4-9)$ days, $\mathrm{p}<0.001$ ) than in other countries. Only $5 \%$ of the overall population and $\sim 7 \%$ of the low-risk group were fully treated at home. The median duration of hospitalisation was 4 days for patients discharged early and 9 days for those with a longer hospitalisation.

On multivariate analysis, initial therapy with direct oral anticoagulants (DOACs) and cancer strongly predicted both home treatment and early discharge. Admission to university hospitals was significantly

@ERSpublications

Real-life data from the RIETE study suggest only a few patients with pulmonary embolism at low risk of complications were treated at home or hospitalised for $\leqslant 5$ days. Management of PE appeared quite variable in different countries. http://ow.ly/o2b230mD8EY

Cite this article as: Mastroiacovo D, Dentali F, di Micco P, et al. Rate and duration of hospitalisation for acute pulmonary embolism in the real-world clinical practice of different countries: analysis from the RIETE registry. Eur Respir J 2019; 53: 1801677 [https://doi.org/10.1183/13993003.01677-2018]. 
TABLE 1 Multivariate analysis using complete home treatment and early discharge as the dependent variable

Variables (number of patients)

\section{Home versus in hospital therapy} OR (CI)
Early discharge ( $\leqslant 5$ days) or home treatment versus admission $>5$ days $\mathrm{OR}(\mathrm{CI})$

\begin{tabular}{|c|c|c|}
\hline \multicolumn{3}{|l|}{ Clinical characteristics } \\
\hline Age $>65$ years & $0.59(0.46-0.76)^{* * *}$ & $0.77(0.69-0.86)^{* * *}$ \\
\hline Male sex $(n=5413)$ & & $1.19(1.08-1.32)^{* * *}$ \\
\hline Body weight <75 kg & & $1.12(1.02-1.24)^{*}$ \\
\hline Pulse $>110$ beats per $\min (n=2214)$ & $0.33(0.23-0.48)^{* * *}$ & $0.62(0.55-0.71)^{* * *}$ \\
\hline Systolic BP levels <100 mmHg ( $\mathrm{m}=888$ ) & $0.50(0.26-0.93)^{*}$ & \\
\hline Temperature $<36^{\circ} \mathrm{C}(\mathrm{n}=756)$ & & $0.82(0.68-0.99) *$ \\
\hline Immobility $\geqslant 4$ days ( $n=1663$ ) & & $0.82(0.71-0.95)^{* *}$ \\
\hline Oestrogen therapy $(n=630)$ & & $1.68(1.37-2.07)^{* * *}$ \\
\hline \multicolumn{3}{|l|}{ Underlying conditions } \\
\hline Chronic heart failure $(n=931)$ & & $0.74(0.61-0.89)^{* *}$ \\
\hline Chronic lung disease $(n=1598)$ & & $0.80(0.70-0.92)^{* *}$ \\
\hline Creatinine clearance levels $<60 \mathrm{~mL} \cdot \mathrm{min}^{-1}(\mathrm{n}=3963)$ & & $0.81(0.72-0.91)^{* * *}$ \\
\hline Israel (n=429) & $0.36(0.13-0.97)^{*}$ & $2.12(1.68-2.67)^{* * *}$ \\
\hline Other countries ( $n=1217)$ & $11.50(9.02-14.66)^{* * *}$ & $2.25(1.93-2.62)^{* * *}$ \\
\hline \multicolumn{3}{|l|}{ Initial therapy } \\
\hline LMWH (n=9935) & Ref. ${ }^{* * *}$ & Ref.*** \\
\hline Unfractionated heparin ( $n=647)$ & $0.16(0.07-0.35)^{* * *}$ & $0.36(0.28-0.46)^{* * *}$ \\
\hline Thrombolytics ( $\mathrm{n}=328$ ) & & $0.35(0.24-0.50)^{* * *}$ \\
\hline DOACs $(n=196)$ & $5.26(3.36-8.24)^{* * *}$ & $2.92(2.08-4.09)^{* * *}$ \\
\hline Fondaparinux $(\mathrm{n}=297)$ & $0.41(0.25-0.67)^{* * *}$ & \\
\hline \multicolumn{3}{|l|}{ Type of hospital } \\
\hline University hospital (n=7025) & $2.29(1.74-3.01)^{* * *}$ & $1.11(1.01-1.23)^{*}$ \\
\hline \multicolumn{3}{|l|}{ Scores } \\
\hline PESI <85 points ( $n=4792$ ) & $1.20(0.98-1.47)$ & $1.33(1.21-1.46)^{* * *}$ \\
\hline RIETE $<1$ point ( $n=3347)$ & $1.29(1.04-1.60)^{*}$ & $1.57(1.42-1.74)^{* * *}$ \\
\hline
\end{tabular}

associated with home treatment and showed a tendency towards a shorter hospital stay. Use of oestrogenic therapy was solely a predictor of early discharge.

When scores were entered one by one in the model, results concerning all previous variables were comparable except for the weight of a number of comorbidities and initial presentation parameters (data not shown). Low PESI or low ACCP scores were not associated with home treatment, both resulting uniquely as weak predictors of a shorter LOS. Low RIETE score weakly predicted both home treatment and early discharge (table 1).

Considering this real-life data collected from several countries, overall, only one in every 13 patients eligible for home treatment was treated at home and less than half of the low-risk population was hospitalised for $\leqslant 5$ days.

These results are not surprising since, until now, the level of evidence on outpatient treatment remains limited by the lack of high-quality research [5]. The variable approaches observed among countries may reflect different healthcare systems and facilities across European and world countries. Various scores, classifying dissimilar low-risk patients, were tested in our cohort, but none of them appeared clearly related to outpatient treatment. It remains to be verified if, in the near future, further validations of well performing clinical prediction rules, such as the Hestia clinical criteria, may help to increase the rate of 
outpatient-treated patients in real-life settings, reducing barriers concerning this practice [6]. The ongoing HOME-PE trial might clarify if a strategy based on the Hestia rule, compared with a strategy based on the simplified-PESI score, is at least as safe with regards to the 30-day rate of adverse events and more effective with regards to the rate of patients eligible for outpatient treatment [7].

Interestingly, in our study, cancer patients were more frequently treated at home or promptly discharged despite evident higher haemorrhagic and thrombotic risk [8]. Notably, incidentally detected asymptomatic cancer-related PE were not included in the population analysed. Commonly, cancer patients may be monitored by oncologists with close follow-up visits and such well-defined assistance programmes may facilitate either an outpatient strategy or a post-discharge management. At the same time, this category of patients may achieve more benefits from home treatment, since a new hospitalisation usually deteriorates their quality of life [9].

As expected, initial treatment with DOACs appeared correlated with outpatient treatment and a shorter LOS. At the time of data collection, only 196 patients in the initial phase of therapy and 996 in the long-term period were treated with DOACs. These drugs, especially those permitting the "single drug approach", may broadly facilitate a quick discharge from emergency wards after a comprehensive risk assessment of PE patients [10-13]. The ongoing Mercury-PE trial, designed to test the hypothesis that management with rivaroxaban, if compared with standard care, reduces the number of initial and subsequent hospitalisation days of low-risk PE, will probably confirm these findings [14]. However, in this observational analysis we are not able to exclude that, in daily clinical practice, DOACs were mainly preferred in the acute phase of treatment for less complex subgroups of patients.

Finally, additional considerations should be taken into account. Up until the end of 2013, the previous guidelines only suggested early discharge for low-risk PE [15] and use of DOACs was not allowed in most countries. From 2014, for the first time, the European Society of Cardiology guidelines suggested both use of DOACs and home treatment for low-risk PE patients [1]. In analysing data from 2010 to 2016, we are probably observing a period of great change with regards to managing PE. Our results relating to academic institutions may suggest that, in these centres, guideline recommendations could potentially be implemented more easily and quickly than in other institutions since a paradigm shift requires more time to be adopted in all clinical settings.

Our study has some limitations. Principally, RIETE is an ongoing observational registry. Therefore, our findings should be treated with caution considering the limitations of observational studies. Moreover, the data collected from multiple centres in different countries participating in the RIETE registry may not be representative of the general treatment in those countries and only patients evaluated in a specific setting may be included. Thus, our data can not be fully generalisable nor used as proof for implementing our results into daily clinical practice.

In the near future, diagnostic and therapeutic advances may be able to optimise low-risk PE patient selection and at the same time improve the management of this disease, providing an approach as safe as and more cost-effective than the current one.

Daniela Mastroiacovo ${ }^{1}$, Francesco Dentali $\odot^{2}$, Pierpaolo di Micco ${ }^{3}$, Ana Maestre ${ }^{4}$, David Jiménez $\odot^{5}$, Silvia Soler ${ }^{6}$, Joan Carles Sahuquillo ${ }^{7}$, Peter Verhamme ${ }^{8}$, Ángeles Fidalgo ${ }^{9}$, Juan Bosco López-Sáez ${ }^{10}$, Andris Skride ${ }^{11}$ and Manuel Monreal ${ }^{12}$, for the RIETE Investigators ${ }^{13}$

${ }^{1}$ Angiology Unit, Ospedale SS. Filippo e Nicola, Avezzano, Italy. ${ }^{2}$ Dept of Clinical Medicine, Insubria University, Varese, Italy. ${ }^{3}$ Dept of Internal Medicine and Emergency Room, Ospedale Buon Consiglio Fatebenefratelli, Naples, Italy. ${ }^{4}$ Dept of Internal Medicine, Hospital Vinalopo Salud, Alicante, Spain. ${ }^{5}$ Respiratory Dept, Ramon y Cajal Hospital and Instituto Ramon y Cajal de Investigacion Sanitaria IRYCIS, Madrid, Spain. ${ }^{6}$ Dept of Internal Medicine, Hospital Olot i Comarcal de la Garrotxa, Gerona, Spain. ${ }^{7}$ Dept of Internal Medicine, Hospital Municipal de Badalona, Barcelona, Spain. ${ }^{8}$ Vascular Medicine and Haemostasis, University of Leuven, Leuven, Belgium. ${ }^{9}$ Dept of Internal Medicine, Hospital Universitario de Salamanca, Salamanca, Spain. ${ }^{10}$ Dept of Internal Medicine, Hospital Universitario de Puerto Real, Cadiz, Spain. ${ }^{11}$ Dept of Cardiology, Ospedale Pauls Stradins Clinical University Hospital, Riga, Latvia. ${ }^{12}$ Dept of Internal Medicine, Hospital Universitario Germans Trias i Pujol de Badalona, Universidad Catolica de Murcia, Barcelona, Spain.

${ }^{13} \mathrm{~A}$ full list of the RIETE investigators can be found at the end of this research letter.

Correspondence: Francesco Dentali, Dept of Clinical Medicine, Insubria University, Viale Borri 57, Varese, 21100, Italy. E-mail: fdentali@libero.it

Received: Jan 142018 | Accepted after revision: Oct 302018

Acknowledgements: We express our gratitude to Sanofi Spain for supporting this Registry with an unrestricted educational grant. We also express our gratitude to Bayer Pharma AG for supporting this Registry. Bayer Pharma AG's support was limited to the part of RIETE outside Spain, which accounts for a $24.01 \%$ of the total patients included in the RIETE Registry. We also thank the RIETE Registry Coordinating Centre, S \& H Medical Science Service, for their quality control data, logistic and administrative support. 
Coordinator of the RIETE Registry: Manuel Monreal (Spain). RIETE Steering Committee Members: Hervè Decousus (France); Paolo Prandoni (Italy); Benjamin Brenner (Israel). RIETE National Coordinators: Raquel Barba (Spain); Pierpaolo Di Micco (Italy); Laurent Bertoletti (France); Inna Tzoran (Israel); Abilio Reis (Portugal); Henri Bounameaux (Switzerland); Radovan Malý (Czech Republic); Philip Wells (Canada); Peter Verhamme (Belgium). RIETE Registry Coordinating Center: S \& H Medical Science Service.

Members of the RIETE Group are as follows. Spain: Adarraga MD, Aibar MA, Alfonso M, Álvarez F, Arcelus JI, Ballaz A, Baños P, Barba R, Barrón M, Barrón-Andrés B, Bascuñana J, Blanco-Molina A, Camón AM, Chasco L, Cruz AJ, del Pozo R, de Miguel J, del Toro J, Díaz-Pedroche MC, Díaz-Peromingo JA, Escribano JC, Falgá C, Fernández-Aracil C, Fernández-Capitán C, Fidalgo MA, Font C, Font L, García MA, García-Bragado F, García-Morillo M, García-Raso A, Gavín O, Gaya I, Gómez C, Gómez V, González J, Grau E, Guijarro R, Gutiérrez J, Hernández-Comes G, Hernández-Blasco L, Hernando E, Jara-Palomares L, Jaras MJ, Jiménez D, Jiménez R, Joya MD, Lima J, Llamas P, Lobo JL, López-Jiménez L, López-Reyes R, López-Sáez JB, Lorente MA, Lorenzo A, Lumbierres M, Madridano O, Maestre A, Marchena PJ, Martín M, Martín-Martos F, Martín-Romero M, Martínez C, Monreal M, Morales MV, Nieto JA, Nieto S, Núñez A, Núñez MJ, Odriozola M, Olivares MC, Otalora S, Otero R, Pardo V, Pedrajas JM, Pellejero G, Pérez-Ductor C, Peris ML, Pons I, Porras JA, Ramírez L, Reyes R, Riera-Mestre A, Riesco D, Rivas A, Rodríguez-Dávila MA, Rosa V, Ruiz-Artacho P, Sahuquillo JC, Sala-Sainz MC, Sampériz A, Sánchez-Martínez R, Soler S, Suriñach JM, Tolosa C, Torres MI, Trujillo-Santos J, Uresandi F, Usandizaga E, Valero B, Valle R, Vela J, Vicente MP, Vilar C, Villalobos A. Belgium: Vanassche T, Vandenbriele C, Verhamme P. Brazil: Yoo HHB. Canada: Wells P. Czech Republic: Hirmerova J, Malý R. Ecuador: Salgado E, Sánchez GT. France: Bertoletti L, Bura-Riviere A, Falvo N, Farge-Bancel D, Hij A, Mahé I, Moustafa F, Quere I. Israel: Braester A, Brenner B, Ellis M, Tzoran I. Italy: Antonucci G, Barillari G, Bilora F, Bortoluzzi C, Brandolin B, Bucherini E, Camerota A, Cattabiani C, Ciammaichella M, Dentali F, Di Micco P, Duce R, Giorgi-Pierfranceschi M, Grandone E, Imbalzano E, Lessiani G, Maida R, Mastroiacovo D, Pace F, Pesavento R, Pinelli M, Poggio R, Prandoni P, Quintavalla R, Rocci A, Siniscalchi C, Tiraferri E, Tonello D, Visonà A. Latvia: Gibietis V, Skride A, Vitola B. Republic of Macedonia: Zdraveska M. Switzerland: Alatri A, Bounameaux H, Calanca L, Mazzolai L.

Conflict of interest: None declared.

\section{References}

1 Konstantinides SV, Torbicki A, Agnelli G, et al. 2014 ESC guidelines on the diagnosis and management of acute pulmonary embolism. Eur Heart J 2014; 35: 3033-3069.

2 Kearon C, Akl EA, Ornelas J, et al. Antithrombotic therapy for VTE disease: CHEST guideline and expert panel report. Chest 2016; 149: 315-352.

3 Aujesky D, Obrosky DS, Stone RA, et al. Derivation and validation of a prognostic model for pulmonary embolism. Am J Respir Crit Care Med 2005; 172: 1041-1046.

4 Maestre A, Trujillo-Santos J, Riera-Mestre A, et al. Identification of low-risk patients with acute symptomatic pulmonary embolism for outpatient therapy. Ann Am Thorac Soc 2015; 12: 1122-1129.

5 Zondag W, Kooiman J, Klok FA, et al. Outpatient versus inpatient treatment in patients with pulmonary embolism: a meta-analysis. Eur Respir J 2013; 42: 134-144.

6 Zondag W, Mos IC, Creemers-Schild D, et al. Outpatient treatment in patients with acute pulmonary embolism: the Hestia Study. J Thromb Haemost 2011; 9: 1500-1507.

7 Roy P-M, Gable B. Hospitalization or out-treatment management of patients with pulmonary embolism: a randomized controlled trial (HOME-PE). https://clinicaltrials.gov/ct2/show/NCT02811237 Date last updated: August 15, 2018

8 Prandoni P, Lensing AW, Piccioli A, et al. Recurrent venous thromboembolism and bleeding complications during anticoagulant treatment in patients with cancer and venous thrombosis. Blood 2002; 100: 3484-3488.

9 Siragusa S, Arcara C, Malato A, et al. Home therapy for deep vein thrombosis and pulmonary embolism in cancer patients. Ann Oncol 2005; 16: Suppl. 4, iv136-iv139.

10 Konstantinides S, Torbicki A. Management of venous thrombo-embolism: an update. Eur Heart J 2014; 35: 2855-2863.

11 Stein PD, Matta F, Hughes PG, et al. Home treatment of pulmonary embolism in the era of novel oral anticoagulants. Am J Med 2016; 129: 974-977.

12 Lankeit M, Konstantinides S. Is it time for home treatment of pulmonary embolism? Eur Respir J 2012; 40: $742-749$

13 Barco S, Lankeit M, Binder $\mathrm{H}$, et al. Home treatment of patients with low-risk pulmonary embolism with the oral factor Xa inhibitor rivaroxaban. Rationale and design of the HoT-PE Trial. Thromb Haemost 2016; 116: 191-197.

14 Singer AJ, Xiang J, Kabrhel C, et al. Multicenter trial of rivaroxaban for early discharge of pulmonary embolism from the emergency department (MERCURY PE): rationale and design. Acad Emerg Med 2016; 23: 1280-1286.

15 Kearon C, Akl EA, Comerota AJ, et al. Antithrombotic Therapy for VTE Disease: Antithrombotic Therapy and Prevention of Thrombosis, 9th ed: American College of Chest Physicians Evidence-Based Clinical Practice Guidelines. Chest 2012; 141: Suppl., e419S-e4194S. 